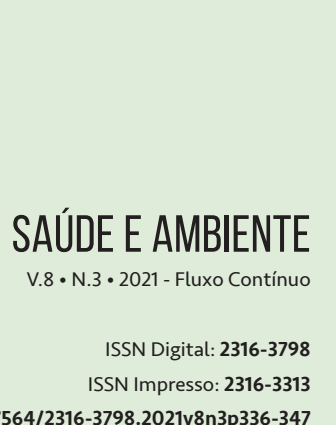

DOI: 10.17564/2316-3798.2021v8n3p336-347

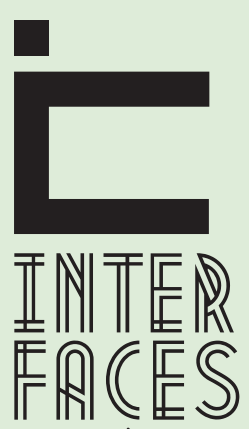

CIENTÍFICAS

\section{MONITORAMENTO DOS PARÂMETROS MICROBIOLÓGICOS DA ÁGUA DE CISTERNAS EM ESCOLAS PÚBLICAS DE POCINHOS}

MONITORING OF MICROBIOLOGICAL PARAMETERS OF CISTERN WATER IN PUBLIC SCHOOLS IN POCINHOS

MONITOREO DE PARÁMETROS MICROBIOLÓGICOS DEL AGUA DE CISTERNA EN ESCUELAS PÚBLICAS DE POCINHOS
Aldeni Barbosa da Silva ${ }^{1}$

Edmilson Dantas da Silva Filho ${ }^{2}$

Bruno Allison Araújo ${ }^{3}$

Janaina Moreira de Brito ${ }^{4}$

Jeferson Freire da Silva ${ }^{5}$

Emmily Tainara de Lima Silva e Silva ${ }^{6}$

Eliane Tâmara Lima Oliveira ${ }^{7}$ Kayan Barbosa Barros ${ }^{8}$

Samanta Gomes Lima de Andrade ${ }^{9}$

Manuela Luiza Belmino dos Santos ${ }^{10}$

\section{RESUMO}

Este trabalho teve o objetivo de monitorar os parâmetros microbiológicos da água de cisternas nas escolas públicas de Pocinhos/PB. As amostras de água destinadas para as análises microbiológicas foram coletadas, diretamente, das cisternas em garrafas de vidro $(500 \mathrm{ml})$ com boca larga, protegidas com papel laminado, previamente, esterilizadas em autoclave a $121^{\circ} \mathrm{C}$, por 30 minutos e foram encaminhadas para o Laboratório do Centro de Formação Profissional do Instituto Albano Franco de Tecnologia de Couro e de Calçado (CTCC) em Campina Grande/PB. Os parâmetros analisados foram: coliformes totais, coliformes termotolerantes, Escherichia coli e bactérias heterotróficas. As amostras foram coletadas in loco e identificadas como amostras 1, 2, 3, 4 e 5. Observou-se que, entre as amostras analisadas, três delas (1, 4 e 5) apresentaram quantidade de coliformes totais, acima dos limites estabelecidos pela Portaria do Ministério da Saúde de $n^{\circ} 5$, de 28 de setembro de 2017 . Todas as amostras apresentaram coliformes termotolerantes. Não se evidenciou a presença de Bactérias heterotróficas. A presença da bactéria E. coli, considerada indicativo de contaminação fecal, foi evidenciada em duas amostras. Conclui-se que todas as amostras estão em desacordo com as recomendações estipuladas pela legislação vigente, pois apresentaram coliformes totais, coliformes termotolerantes e/ou E. coli, denotando em uma inadequada qualidade para o consumo humano.

\section{PALAVRAS-CHAVE}

Coliformes. Escherichia coli. Bactérias Heterotróficas. Monitoramento. 


\section{ABSTRACT}

This work aimed to monitor the microbiological parameters of water from cisterns in public schools in Pocinhos, PB. The water samples destined for microbiological analysis were collected directly from the cisterns in glass bottles $(500 \mathrm{ml})$ with wide mouth, protected with laminated paper, previously sterilized in an autoclave at $121^{\circ} \mathrm{C}$ for 30 minutes and were sent to the Laboratory of the Professional Training Center of the Albano Franco Institute of Leather and Footwear Technology (CTCC) in Campina Grande, PB. The parameters analyzed were: total coliforms, thermotolerant coliforms, Escherichia coli and heterotrophic bacteria. The samples were collected in loco and identified as samples 1, 2, 3, 4 and 5 . It was observed that, among the samples analyzed, three of them (1, 4 and 5) had a quantity of total coliforms, above the limits established by the Ordinance of the Ministry of Health No. 5, of September 28, 2017. All samples had thermotolerant coliforms. There was no evidence of the presence of heterotrophic bacteria. The presence of the $E$. coli bacteria, considered indicative of fecal contamination, was evidenced in two samples. It is concluded that all samples are in disagreement with the recommendations stipulated by the current legislation, as they presented total coliforms, thermotolerant coliforms and/or E. coli, showing an inadequate quality for human consumption.

\section{KEYWORDS}

Coliforms, Escherichia coli, Heterotrophic Bacteria, monitoring.

\section{RESUMEN}

Este trabajo tuvo como objetivo monitorear los parámetros microbiológicos del agua de las cisternas en las escuelas públicas de Pocinhos, PB. Las muestras de agua destinadas al análisis microbiológico se recolectaron directamente de las cisternas en botellas de vidrio $(500 \mathrm{ml})$ de boca ancha, protegidas con papel laminado, previamente esterilizadas en autoclave a $121^{\circ} \mathrm{C}$ durante 30 minutos y fueron enviadas al Laboratorio de Formación Profesional. Centro del Instituto de Tecnología del Cuero y Calzado Albano Franco (CTCC) en Campina Grande, PB. Los parámetros analizados fueron: coliformes totales, coliformes termotolerantes, Escherichia coli y bacterias heterótrofas. Las muestras fueron recolectadas in loco e identificadas como muestras 1, 2, 3, 4 y 5. Se observó que, entre las muestras analizadas, tres de ellas (1, 4 y 5 ) tenían una cantidad de coliformes totales, por encima de los límites, establecido por Ordenanza del Ministerio de Salud No. 5, de 28 de septiembre de 2017. Todas las muestras tenían coliformes termotolerantes. No hubo evidencia de la presencia de bacterias heterótrofas. La presencia de la bacteria E. coli, considerada indicativa de contaminación fecal, se evidenció en dos muestras. Se concluye que todas las muestras están en desacuerdo con las recomendaciones 
estipuladas por la legislación vigente, por presentar coliformes totales, coliformes termotolerantes y / o E. coli, presentando una calidad inadecuada para el consumo humano.

\section{PALABRAS CLAVE}

Coliformes, Escherichia coli, Bacterias heterótrofas, seguimiento.

\section{INTRODUCÇÃO}

A água é o principal constituinte para o funcionamento do planeta. Ela faz parte de todos os elementos vivos, sendo importante nas reações químicas e no transporte de substâncias. Porém, apenas $0,77 \%$ de toda essa água é a quantidade que podemos aproveitar (SANTOS et al., 2018; SILVA FILHO et al., 2020).

Da mitologia ao dia a dia, a água está em todas as dimensões de nossa existência. Nos últimos dois séculos, porém, transformamos radicalmente nossa relação com a água. Fomos capazes de transpor a gravidade para utilizá-la, retirá-la de aquíferos profundos, armazená-la em grandes quantidades, dominar rios, irrigar locais áridos para produzir alimentos e poluí-la com uma variedade enorme de substâncias. Também nos desacostumamos a pensar de onde vem ou para onde vai a água que consumimos (WHATELY; CAMPANILI, 2016; SILVA et al., 2020a).

A água potável limpa, segura e adequada é vital para a sobrevivência de todos os organismos vivos e para o funcionamento dos ecossistemas, comunidades e economias. Mas a qualidade da água em todo o mundo é cada vez mais ameaçada à medida que as populações humanas crescem, atividades agrícolas e industriais se expandem e as mudanças climáticas ameaçam alterar o ciclo hidrológico global (ONU, 2010).

Embora dependam da água para a sobrevivência e para o desenvolvimento econômico, as sociedades humanas poluem e degradam esse recurso, tanto as águas superficiais quanto as subterrâneas. A diversificação dos usos múltiplos, o despejo de resíduos líquidos e sólidos em rios, lagos e represas e a destruição das áreas alagadas e das matas de galeria têm produzido contínua e sistemática deterioração e perdas, extremamente, elevadas em quantidade e em qualidade da água (TUNDISI; MATSUMURA-TUNDISI, 2011).

O controle da qualidade da água é uma necessidade universal, que exige atenção por parte das autoridades sanitárias e dos consumidores em geral, sobretudo no que se refere à água destinada ao consumo humano, visto que ela pode se tornar um veículo capaz de transmitir uma série de agentes patogênicos e substâncias nocivas, influenciando diretamente no bem-estar e na saúde da população (ARAÚJO et al., 2011; WANG et al., 2014; MENDONÇA et al., 2017; SILVA et al., 2020b).

As crianças e adolescentes passam grande parte de seu tempo nas escolas durante o dia, com pelo menos duzentos dias letivos anuais. Esta permanência na escola determina que seja ingerido relevantes quantidades de água. Por isso, a água distribuída nos estabelecimentos escolares obrigatoria- 
mente deve ter qualidade potável de acordo com o preconizado pelo Ministério da Saúde (TRINDADE et al., 2015; SILVA et al., 2019).

A qualidade da água pode ser afetada por fatores como a poluição atmosférica, pelo sistema de coleta da água pluvial, pela manutenção inadequada da cisterna, utilização e manuseio da água e por fatores ligados à origem da água, transportada por carros-pipa, e à vulnerabilidade a que está exposta, sendo que a grande meta da sociedade e do poder público é o estabelecimento de políticas de qualidade de água associadas às políticas de águas, a fim de assegurar a qualidade da mesma (AMORIM; PORTO, 2001; CÂMARA et al., 2019).

Diante disso, esse trabalho teve o objetivo de monitorar os parâmetros microbiológico da água de cisternas nas escolas públicas de Pocinhos/PB.

\section{MATERIAL E MÉTODOS}

\section{1 ÁREA DE ESTUDO}

O estudo foi desenvolvido nas escolas municipais da zona urbana de Pocinhos/PB, cidade situada no Bioma Caatinga, com área territorial de $628,084 \mathrm{~km}^{2}$, apresentando uma população estimada em 18.564 habitantes, densidade demográfica de 27,12 hab $/ \mathrm{km}^{2}$, e coordenadas geográficas de Latitude: $7^{\circ}$ 4' 26" Sul, Longitude: $36^{\circ}$ 3' 40" Oeste (IBGE, 2010). As escolas são abastecidas pela rede de distribuição pública, proveniente do açude Epitácio Pessoa, e o armazenamento interno é feito por meio de cisternas e/ou caixas d'água.

\subsection{AMOSTRAS E PROCEDIMENTOS PARA AS ANÁLISES MICROBIOLÓGICAS}

As amostras de água destinadas para as análises microbiológicas foram coletadas diretamente das cisternas em garrafas de vidro $(500 \mathrm{ml}$ ) com boca larga, protegidas com papel laminado, previamente, esterilizadas em autoclave a $121^{\circ} \mathrm{C}$, por 30 minutos e foram encaminhadas para o Laboratório do Centro de Formação Profissional do Instituto Albano Franco em Campina Grande/PB. As amostras ficaram conservadas à temperatura de 4 a $8^{\circ} \mathrm{C}$ pelo tempo máximo de quatro horas, até o momento da semeadura.

Os parâmetros analisados foram: coliformes totais, coliformes termotolerantes, Escherichia coli e bactérias heterotróficas. Esses parâmetros foram determinados seguindo-se as metodologias da Companhia Ambiental do Estado de São Paulo (CETESB, 2006). Os valores foram avaliados conforme as recomendações da Portaria de Consolidação n 5/2017 do Ministério da Saúde (BRASIL, 2017).

\subsection{CONTAGEM DE BACTÉRIAS HETEROTRÓFICAS: MÉTODO DE ENSAIO}

A técnica de inoculação em profundidade para contagem de bactérias heterotróficas baseia-se na inoculação de volumes adequados da amostra em placas de Petri, com posterior adição do meio de cultura triptona glicose extrato de levedura ("plate count agar"). Após 48 horas de incubação a $35 \pm 0,5^{\circ} \mathrm{C}$, 
as bactérias viáveis presentes na amostra, que puderam se desenvolver nessas condições, formaram colônias que foram contadas com o auxílio de um contador tipo Quebec ou similar (CETESB, 2006).

\subsection{COLIFORMES TOTAIS, COLIFORMES TERMOTOLERANTES E ESCHERICHIA COLI- DETERMINAÇ̃̃O PELA TÉCNICA DE TU- BOS MÚLTIPLOS}

A determinação do número mais provável (NMP) de coliformes em uma amostra foi efetuada a partir de aplicação da técnica de tubos múltiplos. Esta técnica é baseada no princípio de que as bactérias presentes em uma amostra podem ser separadas por agitação, resultando em uma suspensão de células bacterianas, uniformemente distribuídas na amostra. A técnica consiste na inoculação de volumes decrescentes da amostra em meio de cultura adequado ao crescimento dos microrganismos pesquisados, sendo cada volume inoculado em uma série de tubos.

Por meio de diluições sucessivas da amostra, são obtidos inóculos, cuja semeadura fornece resultados negativos em pelo menos um tubo da série em que eles serão inoculados; e a combinação de resultados positivos e negativos permite a obtenção de uma estimativa de densidade das bactérias pesquisadas pela aplicação de cálculos de probabilidade. Para análise de água, tem sido utilizado, preferencialmente, o fator 10 de diluição, sendo inoculados múltiplos e submúltiplos de $1 \mathrm{~mL}$ da amostra, usando-se séries de cinco tubos para cada volume a ser inoculado (CETESB, 2018).

O exame para determinação de coliformes totais se processa por meio de duas etapas (ensaios presuntivo e confirmativo) de realização obrigatória para todos os tipos de amostras de água, as quais são complementadas, quando indicado, por uma terceira etapa (exame completo). A densidade de coliformes termotolerantes ou $E$. coli foi obtida a partir de um exame específico, aplicado paralelamente ao teste para confirmação de coliformes totais.

\subsection{ENSAIO PARA DIFERENCIAÇ̃̃O DE COLIFORMES TERMOTOLERANTES OU E. COLI}

Consiste na transferência de inóculo de cada cultura com resultado positivo em caldo laurel triptose (CLT) com púrpura de bromocresol para tubos contendo meio EC (coliformes termotolerantes) ou EC MUG ( $E$. coli $)$, que foram incubados durante $24 \pm 2$ horas em banho-maria ou incubadora a 44,5 $\pm 0,2^{\circ} \mathrm{C}$. O resultado para coliformes termotolerantes será positivo quando houver produção de gás a partir da fermentação da lactose contida no meio EC ou para E. coli, quando houver fluorescência azul sob lâmpada ultravioleta de comprimento de onda 365 - 366 nm em ambiente escuro.

\section{RESULTADOS E DISCUSSÃO}

Com base no critério de potabilidade estabelecido pela Portaria de Consolidação nº 5/2017 do Ministério da Saúde (BRASIL, 2017), observou-se que três das amostras analisadas apresentaram quantidade de coliformes totais fora dos limites estabelecidos pela portaria vigente e apenas duas dentro dos padrões determinados (Tabela 1). 
Tabela 1 - Coliformes totais, coliformes termotolerantes, Escherichia coli e Bactérias heterotróficas nas amostras de água coletada nas cisternas das escolas municipais de Pocinhos/PB

\begin{tabular}{ccccc}
\hline Amostras & $\begin{array}{c}\text { Coliformes } \\
\text { totais * }\end{array}$ & $\begin{array}{c}\text { Coliformes } \\
\text { termotolerantes }\end{array}$ & $\begin{array}{c}\text { Escherichia } \\
\text { coli }\end{array}$ & $\begin{array}{c}\text { Bactérias } \\
\text { heterotróficas } \\
(\mathbf{1 0 0} \text { UFC/ml)** }\end{array}$ \\
\hline 1 & $>8,0$ & $>8,0$ & $>8,0$ & 43 \\
2 & $<1,1$ & $>8,0$ & $<1,1$ & 11 \\
3 & $<1,1$ & $>8,0$ & $<1,1$ & 68 \\
4 & $>8,0$ & $>8,0$ & $>8,0$ & 300 \\
5 & $>8,0$ & $>8,0$ & $<1.1$ & 79 \\
\hline Especificação & Ausente & Ausente & Ausente & $500 \mathrm{UFC} / \mathrm{ml}$ \\
\hline
\end{tabular}

* Segundo a Portaria PRC n 5, de 28 de setembro de 2017 (BRASIL, 2017)

** UFC/ml - Unidade formadora de colônias

***Na metodologia dos tubos múltiplos o resultado $<1,8$, significa ausência de coliformes na amostra ensaiada.

Fonte: Dados da pesquisa.

Coliformes totais são uma classe de bactérias que possui como principal característica a fermentação de lactose com produção de ácidos, aldeídos e gás a $35^{\circ} \mathrm{C}$ entre 24 e 48 horas (PORTO et al., 2011; BEAL et al., 2014; ALVES et al., 2018).

Além de infecções intestinais, os coliformes totais podem estar envolvidos ou ter participação em diversas outras patologias, como meningites, intoxicações alimentares, infecções urinárias e pneumonias, inclusive as nosocomiais. Infecções causadas por esses organismos são complexas e envolvem múltiplos modos de transmissão. Alguns gêneros como Enterobacter, Citrobacter, Klebisiella e Serratia, vivem na água, no solo e, também, constituem a microbiota intestinal do homem, assim como a de outros animais de sangue quente (KONEMAN et al., 2001).

Resultados diferentes foram encontrados por Silva Filho e colaboradores (2020) que não detectaram resultados positivos para coliformes totais ao verificarem a qualidade da água do açude Epitácio Pessoa, Boqueirão, PB, Brasil. Porém, Moreira e Campolino (2017) verificaram a presença de coliformes totais em todas as amostras, quando realizaram a análise de coliformes totais em água de cisternas no município de Inhaúma/MG. Rodrigues e Siqueira (2018) observaram que na primeira e segunda coleta todas as amostras foram positivas para coliformes totais, quando estudaram os riscos biológicos associados à água de cisternas no município de Serra Talhada/PE.

Siqueira e colaboradores (2010) observaram que 62,5\% das amostras analisadas apresentaram coliformes totais e 42,5\% apresentaram coliformes termotolerantes, quando realizaram a avaliação microbiológica da água de consumo empregada em unidades de alimentação localizadas no entorno da Universidade Federal Rural de Pernambuco (UFRPE) e da Universidade Federal de Pernambuco (UFPE). De acordo 
com os autores, essas amostras são consideradas impróprias para o consumo humano, pois a presença de coliformes na água indica poluição, com o risco potencial da presença de organismos patogênicos.

Em relação aos coliformes termotolerantes, todas as amostras apresentaram resultados positivos (Tabela 1). A Portaria de Consolidação n 5/2017 do Ministério da Saúde determina ausência de coliformes termotolerantes em cada $100 \mathrm{~mL}$ de amostra de águas destinadas ao consumo e, por essa razão, nenhuma dessas amostras pode ser considerada própria para consumo humano (BRASIL, 2017).

Esses resultados se mostram semelhantes aos descritos por Nogueira e colaboradores (2003) para águas tratadas pelo sistema público e coletadas na região de Maringá/PR. Silva e colaboradores (2019) observaram a presença de coliformes termotolerantes em três amostras quando realizaram a análise microbiológica da água de bebedouros nas escolas públicas da cidade de Esperança/PB.

Rodrigues e colaboradores (2019) encontraram contaminação para coliformes totais em todos os 6 pontos de coleta e coliformes termotolerantes em 1 dos pontos, quando fizeram o levantamento e análises das fontes alternativas de captação de água utilizadas no abastecimento de uma população rural de Visconde do Rio Branco, MG.

Amplamente distribuídos na natureza, os coliformes se propagam com maior frequência na água, especialmente, os coliformes termotolerantes, de origem fecal, que têm tido grande atenção da saúde pública. Os coliformes termotolerantes estão associados a um elevado número de patologias cujos agentes etiológicos são isolados em laboratórios de microbiologia clínica e, diretamente, considerados o motivo da maioria das infecções intestinais humanas conhecidas (HOFSTRA; HUISIN'T VELD, 1988; YAMAGUCHI et al., 2013).

Observou-se que em duas amostras foram detectadas presença de Escherichia coli(Tabela 1) e, de acordo com a Portaria de Consolidação n 5/2017 do Ministério da Saúde, foi determinada ausência de E. coli nas amostras ensaiadas (BRASIL, 2017).

A E. colié uma bactéria pertencente ao grupo coliforme, que tem como habitat primário o intestino do homem e de animais de sangue quente, representando 95\% das bactérias do grupo coliformes encontradas nas fezes humanas e de animais. Por ser uma bactéria de fácil isolamento e identificação em água e por seu período de sobrevivência ser semelhante ao dos patógenos mais comuns, a $E$. coli é considerada a melhor indicadora de contaminação fecal, sendo a tendência atual o uso da detecção específica de E. coli, e não mais de bactérias do grupo coliformes termotolerantes (JAY, 2005; SILVA et al., 2005; MARQUEZI et al., 2010).

Resultados diferentes foram observados por Silva e colaboradores (2017), que ao realizarem a análise microbiológica da água utilizada para consumo nas Escolas de Esperança/PB, não detectaram a presença de $E$. coli, porém, evidenciaram a presença de coliformes totais, e por Seco e colaboradores (2012) que não encontraram coliformes totais nem E. coli em todas as 19 amostras colhidas nos bebedouros do campus da Universidade Estadual de Londrina.

Não se detectou a presença de Bactérias Heterotróficas (Tabela 1). De acordo com a Portaria de Consolidação n 5/2017 do Ministério da Saúde é permitido até 500 UFC/ml (Unidade Formadora de Colônias) (BRASIL, 2017).

As bactérias heterotróficas estão presentes em todos os tipos de água, nos alimentos, no solo, na vegetação e no ar. Sua contagem pode fornecer uma indicação geral sobre a qualidade microbiológica 
da água tratada, e quando realizada regularmente pode demonstrar alterações devido ao armazenamento (recrescimento, formação de biofilme), eficiência dos métodos de tratamento, integridade e limpeza do sistema de distribuição (WHO, 2003).

Resultados diferentes foram encontrados por Silva Filho e colaboradores (2020), que observaram uma quantidade de bactérias heterotróficas fora dos limites estabelecidos pela Portaria de Consolidação n 5/2017, ao verificarem a qualidade da água do açude Epitácio Pessoa, Boqueirão, PB, Brasil.

Bortoloti e colaboradores (2018), quando estudaram a qualidade microbiológica de águas naturais quanto ao perfil de resistência de bactérias heterotróficas a antimicrobianos, observaram que, entre as fontes analisadas, quatro delas (3, 5, 6 e 11) apresentaram, em ambas as estações (seca e chuvosa), quantidade de bactérias heterotróficas dentro dos limites estabelecidos pela portaria vigente, e as demais fontes já utilizadas para consumo humano (4, 7 e 8) apresentaram, em pelo menos um período, chuvoso ou seco, contagens de bactérias heterotróficas insatisfatórias.

\section{CONCLUSÃO}

Conclui-se que todas as amostras estão em desacordo com as recomendações estipuladas pela Portaria de Consolidação no 5/2017 do Ministério da Saúde, pois apresentaram coliformes totais, coliformes termotolerantes e/ou Escherichia coli, necessitando, portanto, de tratamento prévio antes de serem fornecidas para consumo humano.

\section{REFERÊNCIAS}

ALVES, S. G. S. et al. Análise microbiológica de coliformes totais e termotolerantes em água de bebedouros de um parque público de Brasília, Distrito Federal. Rev Cient Sena Aires, v. 7, n. 1, p. 12-17, 2018.

AMORIM, M. C. C.; PORTO, E. R. Avaliação da qualidade bacteriológica das águas de cisternas: estudo de caso no município de Petrolina - PE. Simpósio Brasileiro de Captação de Água de Chuva no Semiárido, 3, 2001. Anais [...], Campina Grande, PB, 2001.

ARAÚJO, G. F. R. et al. Qualidade físico-química e microbiológica da água para o consumo humano e a relação com a saúde: estudo em uma comunidade rural no estado de São Paulo. 0 Mundo da Saúde, v. 35, n. 1, p. 98-104, 2011.

BEAL, D. A. et al. Recursos hídricos: uso de água na indústria - o caso de dois vizinhos no Paraná. Congresso Nacional de Pesquisa em Ciências Sociais Aplicadas, 3, 2014. Anais [...], Toledo, PR, 2014. 
BORTOLOTI, K. C. S. et al. Qualidade microbiológica de águas naturais quanto ao perfil de resistência de bactérias heterotróficas a antimicrobianos. Eng Sanit Amb., v. 23, n. 4, p. 717-725, 2018.

BRASIL. Ministério da Saúde. Portaria de Consolidação nº 5 de 28 de setembro de 2017. Brasília: Ministério da Saúde, 2017.

CÂMARA, J. C. S. et al. Fiscalização microbiológica da água de cisternas nas escolas públicas da cidade de Esperança-PB. Simpósio de Pesquisa, Inovação e Pós-graduação do IFPB, 3, 2019. Anais[...], João Pessoa, PB, 2019.

CETESB - Companhia de Tecnologia de Saneamento Ambiental de São Paulo. Norma técnica L5.202. Coliformes totais, coliformes termotolerantes e Escherichia coli- Determinação pela técnica de tubos múltiplos. 5ª Ed. São Paulo: CETESB. 2018.

CETESB - Companhia de Tecnologia de Saneamento Ambiental de São Paulo. Norma técnica L5.201. Contagem de bactérias heterotróficas: método de ensaio. São Paulo: CETESB, 2006.

HOFSTRA, H.; HUISIN'T VELD, J. H. J. Methods for the detection and isolation of Escherichia coli including pathogenic strains. J App Bacteriol., v. 65 (Suppl), p. 197S-212S, 1988.

IBGE - Instituto Brasileiro de Geografia e Estatistica. @Cidades, 2010. Disponível em: https:// cidades.ibge.gov.br/brasil/pb/pocinhos/panorama. Acesso em: 12 fev. 2020.

JAY, J. M. Microbiologia de alimentos. 6. ed. Porto Alegre: Artmed; 2005.

KONEMAN, E. W. et al. Diagnóstico microbiológico. 5. ed. Rio de Janeiro: MEDSI, 2001.

MARQUEZI, M. C. et al. Comparação entre métodos para a análise de coliformes totais e $E$. coli em amostras de água. Rev Inst Adolfo Lutz, v. 69, n. 3, p. 291-296, 2010.

MENDONÇA, M. H. M. et al. Análise bacteriológica da água de consumo comercializada por caminhões-pipa. Rev Amb Água, v. 12, n. 3, p. 468-475, 2017.

MOREIRA, C. R.; CAMPOLINO, M. Análise de coliformes totais em água de cisternas no município de Inhaúma/MG. Rev Bras Ciên Vida, v. 5, n. 5, 15 p., 2017.

NOGUEIRA, G. et al. Microbiological quality of drinking water of urban and rural communities. Rev Saúde Públ., v. 2, n. 37, p. 232-236, 2003. 
ONU - Organização das Nações Unidas. Declaração da “ONU água” para o dia mundial da água 2010. Brasília, DF: ONUBR. 2016. Disponível em: https://nacoesunidas.org/acao/agua/. Acesso em: 3 abr. 2021.

PORTO, M. A. L. et al. Coliformes em água de abastecimento de lojas fast food da Região Metropolitana de Recife (PE, Brasil). Ciên Saúde Col., v. 16, n. 5, p. 2653-2658, 2011.

RODRIGUES, S. J. S.; SIQUEIRA, V. M. Riscos biológicos associados à água de cisternas no município de Serra Talhada, PE. Rev Nordestina Ciên Biol., v. 1, n. 1, p. 26-34, 2018.

RODRIGUES, A. L. et al. Levantamento e análises das fontes alternativas de captação de água utilizadas no abastecimento de uma população rural de Visconde do Rio Branco-MG. Águas Subterrâneas, v. 31, n. 1, p. 1-6, 2019.

SANTOS, J. S. I. et al. Avaliação dos parâmetros físico-químicos de água fornecida para a comunidade escolar, através de poço tubular, no município de Soledade-PB. Congresso Brasileiro de Águas Subterrâneas, 10, 2018. Anais [...], Campinas, SP. 2018.

SECO, B. M. S. et al. Avaliação bacteriológica das águas de bebedouros do campus da Universidade Estadual de Londrina - PR. Semina Ciên Biol Saúde, v. 33, n. 2, p. 193-200, 2012.

SILVA, A. B. et al. Microbiologia Ambiental: monitoramento bacteriológico da água de um poço artesiano localizado no sítio Bagaceira em Areia-PB. Águas Subterrâneas, v. 34, n. 1, p. 1-7, 2020 a.

SILVA, A. B. et al. Inspeção Microbiológica da água de um poço artesiano localizado no sítio macacos na zona rural de Areia-PB, Brasil. Águas Subterrâneas, v. 34, n. 1, p. 1-7, 2020 b.

SILVA, A. B. et al. Análise Microbiológica da água de bebedouro nas escolas públicas da cidade de Esperança/PB. S Am J Basic Ed Tech Technol., v. 6, n. 1, p. 15-26, 2019.

SILVA, A. B. et al. Análise microbiológica da água utilizada para consumo nas escolas de Esperança, Paraíba. Rev Principia, n. 37, p. 11-17, 2017.

SILVA, N. et al. Manual de métodos de análise microbiológica da água. São Paulo: Varela, 2005.

SILVA FILHO, E. D. et al. Verificação da qualidade da água do açude Epitácio Pessoa, Boqueirão, PB, Brasil. Interf Cient Saúde Amb., v. 8, n. 2, p. 215-229, 2020.

SIQUEIRA, L. P. et al. Avaliação microbiológica da água de consumo empregada em unidades de alimentação. Ciên Saúde Col., v. 15, n. 1, p. 63-66, 2010. 
TRINDADE, G. A. et al. Avaliação da qualidade da água em três escolas públicas da cidade de Macapá, Amapá. Biota Am., v. 5, n. 1, p. 116-122, 2015.

TUNDISI, J. G.; MATSUMURA-TUNDISI, T. Recursos hídricos no século XXI. São Paulo: Oficina de Textos, 2011.

WANG, H. et al. Effect of disinfectant, water age, and pipe materials on bacterial and eukaryotic community structure in drinking water biofilm. Environ Sci Technol., v. 48, n. 3, p. 1426-1435, 2014.

WHATELY, M.; CAMPANILI, M. 0 século da escassez: uma nova cultura de cuidado com a água: impasses e desafios. São Paulo: Claro Enigma, 2016. (Coleção Agenda Brasileira).

WHO - World Health Organization. WHO guidelines for drinking water quality. Geneva: WHO, 2003. Disponível em: http//www.who.int/water_sanitation_health/dwq/guidelines/3rd/en/. Acesso em: 15 dez. 2018.

YAMAGUCHI, M. U. et al. Qualidade microbiológica da água para consumo humano em instituição de ensino de Maringá/PR. 0 Mundo da Saúde, v. 37. n. 3, p. 312-320, 2013. 
1 Doutor em Agronomia; Pós-Doutor em Ciência do Solo; Professor do Instituto Federal de Educação, Ciência e Tecnologia da Paraíba - Campus Esperança/PB.

E-mail: aldeni.silva@ifpb.edu.br

2 Doutor em Engenharia Agrícola; Professor do Instituto Federal de Educação, Ciência e Tecnologia da Paraíba, Campus Campina Grande/PB.

E-mail: edmilson.silva@ifpb.edu.br

3 Doutor em Ciência e Engenharia de Materiais; Professor do Instituto Federal de Educação, Ciência e Tecnologia da Paraíba - Campus Esperança/PB.

E-mail: bruno.araujo@ifpb.edu.br

4 Graduada em Ciências Biológicas - Universidade Federal da Paraíba, Campus II, Areia/PB.

E-mail: janaina.brito1@outlook.com

5 Acadêmico do Curso Técnico em Informática no Instituto Federal de Educação, Ciência e Tecnologia da Paraíba Campus Esperança/PB.

E-mail: jeferson.silva@academico.ifpb.edu.br

6 Acadêmica do Curso Técnico em Informática no Instituto Federal de Educação, Ciência e Tecnologia da Paraíba Campus Esperança/PB.

E-mail: emmily.tainara@academico.ifpb.edu.br

7 Acadêmica do Curso Técnico em Informática no Instituto Federal de Educação, Ciência e Tecnologia da Paraíba Campus Esperança/PB.

E-mail: eliane.tamara@academico.ifpb.edu.br

8 Acadêmico do Curso Técnico em Informática no Instituto Federal de Educação, Ciência e Tecnologia da Paraíba Campus Esperança/PB.

E-mail: kayan.barros@academico.ifpb.edu.br

9 Acadêmica do Curso Técnico em Informática no Instituto Federal de Educação, Ciência e Tecnologia da Paraíba Campus Esperança/PB.

E-mail: samanta.gomes@academico.ifpb.edu.br

10 Acadêmica do Curso Técnico em Informática no Instituto Federal de Educação, Ciência e Tecnologia da Paraíba Campus Esperança/PB.

E-mail: manuela.belmino@academico.ifpb.edu.br
Recebido em: 30 de Junho de 2021

Avaliado em: 29 de Julho de 2021

Aceito em: 29 de Julho de 2021

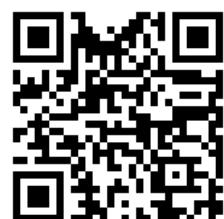

A autenticidade desse artigo pode ser conferida no site https://periodicos. set.edu.br

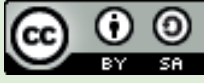

Este artigo é licenciado na modalidade acesso abertosob a Atribuição-Compartilhalgual CC BY-SA

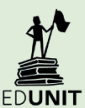

